LIF-LIFR-gp130. Future studies will have to tell whether the proposed common mechanism of receptor activation pertains. Of particular interest are the receptor complexes for leptin and IL-23 (Fig. 1). Because the leptin receptor contains only two FnIII domains, one would have to postulate that a smaller gap between the CHR domains of the two signaling receptor chains must be bridged than in the IL- 6 system. The IL-23R is even more peculiar because it is the only signal transducing receptor subunit 을 of the IL-6/IL-12 family that lacks the membrane- proximal FnIII domains. The ultimate goal, however, needs to be the elucidation of the three-dimensional structure of wild-type receptor complexes in their membraneanchored form.

1. Ballinger, M.D. \& Wells, J.A. Nat. Struct. Biol. 5, 938 940 (1998).

2. Skiniotis, G., Boulanger, M.J., Garcia, K.C. \& Walz, T. Nat. Struct. Mol. Biol. 12, 545-551 (2005).

3. Syed, R.S. et al. Nature 395, 511-516 (1998).

4. Livnah, O. et al. Science 283, 987-990 (1999).

5. Boulanger, M.J., Chow, D.C., Brevnova, E.E. \& Garcia, K.C. Science 300, 2101-2104 (2003).
6. Kurth, I. et al. J. Immunol. 164, 273-282 (2000).

7. Aritomi, M. et al. Nature 401, 713-717 (1999).

8. Layton, J.E., Hall, N.E., Connell, F., Venhorst, J. \& Treutlein, H.R. J. Biol. Chem. 276, 36779-36787 (2001).

9. Hammacher, A. et al. Biochem. J. 345, 25-32 (2000).

10. Livnah, O. et al. Science 273, 464-471 (1996).

11. Livnah, O. et al. Nat. Struct. Biol. 5, 993-1004 (1998).

12. Constantinescu, S.N., Huang, L.J., Nam, H. \& Lodish, H.F. Mol. Cell 7, 377-385 (2001).

13. Greiser, J.S., Stross, C., Heinrich, P.C., Behrmann, I. \& Hermanns, H.M. J. Biol. Chem. 277, 26959-26965 (2002).

14. Schroers, A. et al. Protein Sci. 14, 783-790 (2005).

\title{
Competing for the cap
}

In its first two hours after fertilization the Drosophila embryo develops as a syncytium where nuclei divide without any cellular division. Within the cytoplasm of this multinucleated syncytium, proteins and RNA stored in the egg are localized to different regions. Gradients of these macromolecules specify the dorsal-ventral and anterior-posterior axis of the embryo and thereby the entire body pattern of the mature fly. During the localization process, which involves the transport of mRNA in ribonucleoprotein complexes, translation of the message is inhibited. This ensures that expression of a protein only takes place in the proper region of the embryo.

Translation inhibition most often occurs at the initiation stage when the small subunit of the ribosome is recruited to the cap structure at the $5^{\prime}$ end of the mRNA. This structure interacts with the cap binding complex, eukaryotic initiation factor (elF) $4 \mathrm{~F}$, which is composed of three subunits: elF4E, elF4A, and elF4G. The interaction of elF4G with elF4E and the polyadenosine (polyA) binding protein (PABP) bound at the $3^{\prime}$ end of the mRNA circularizes the transcript and promotes the recruitment of the small subunit of the ribosome for translation. Because of their key roles in initiation, elF4E and PABP are targets for translational control. Cho et al. (Ce/l 121, 411-423, 2005) now identify a new translational inhibition mechanism that involves competition between elF4E and the Drosophila elF4E-Homologous Protein (d4EHP) for the mRNA cap structure.

Although d4EHP shares sequence similarity with elF4E, especially within the cap interaction region, the function of d4EHP has not been clear. Previous work had shown that d4EHP does not interact with elF4G and therefore cannot act like elF4E to promote ribosome recruitment. Using a Drosophila embryo system and a combination of genetic and biochemical tools Cho et al. show that $\mathrm{d} 4 \mathrm{EHP}$ is a cap binding protein that also binds Bicoid, a capdependent translational repressor.

Bicoid binds to the $3^{\prime}$ untranslated region of cad mRNA which encodes Caudal, a protein essential for proper patterning of the embryo. The authors generated transgenic flies that expressed wildtype or mutant d4EHP in a d4EHP mutant background.
In wild-type flies (panel a), Caudal is expressed primarily in the posterior of the embryo (green dots). However, in flies expressing d4EHP that is defective in cap (panel b) or Bicoid binding (panel c), expression of Caudal occurs throughout the embryo. In later stages of development, these embryos exhibit patterning defects. These data show that the interaction of $\mathrm{d} 4 \mathrm{EHP}$ with both the cap structure at the $5^{\prime}$ end of the cad mRNA and with Bicoid at the $3^{\prime}$ region is critical for inhibition of translation and Drosophila development. In this system, d4EHP functions as a competitor of elF4E. When d4EHP wins the competition for the cap, elF4F does not form on the mRNA and translation is inhibited.

There are several mechanisms by which a protein can inhibit translation by interfering with elF4E or PABP. For example, proteins can sequester essential translation initiation factors as in the case of $4 \mathrm{E}-\mathrm{BP}$ which sequesters elF4E from the eukaryotic initiation complex and thereby inhibits cap-dependent translation. Alternatively, proteins can bind to factors at both ends of the mRNA and interfere with eIF4F complex formation. Cup and Maskin interact with elF4E as well as the $3^{\prime}$ end of the mRNA to compete with elF4G for binding to elF4E. Lastly, proteins can displace PABP from the polyA tail and prevent circularization of the mRNA during initiation complex formation. Cho et al. have identified yet another mechanism of translation inhibition and show that proteins can also compete for specific structures within the mRNA. Interestingly, the proposed interaction between d4EHP and Bicoid is very similar to that between elF4E and 4E-BP. Indeed, elF4E and d4EHP appear to share a similar fold, and the primary structure of the binding motif of $4 \mathrm{E}-\mathrm{BP}$ and Bicoid are also related. Therefore it will be interesting to determine the structural differences between the two types of interactions and understand the requirements for selectivity in each system. The results from Cho et al. demonstrate for the first time the involvement of a cap binding protein other than elF4E in cap-dependent translational control and show that the cell uses a combination of mechanisms to control translation.

Evelyn Jabri 